intermediate metabolites in the urine, the stiffness of the muscles, and other symptoms, lead us to believe that such products of metabolic activity are inefficiently removed from the system. The introduction of more fluid would remedy this deficiency of excretion, which we hold to be of far greater importance than deficiency of nutrition.

Repeated experience contradicts the popular conviction that large quantities of food must be taken in order to "keep up the strength" in contests of this kind. For instance, soldiers bearing heavy clothing and equipment have frequently marched for many hours with no food, provided that a sufficiency of water is available. Experiments on animals, too, show that external work can be performed for some days on a water diet only.

These facts serve to justify us in advising the consumption of little or no solid food during the race; we think that in this way the gastric disturbances would be entirely obviated. In order to avoid the depressing mental effect consequent upon the withholding of all food, albumen water, or some such preparation might be given. This would only be as a concession to the men's preconceived ideas, and not with the object of providing nutriment. The use of a little alcobol as a readily diffusible and oxidizable stimulant in the last stages of the race seems to ke free from objection.

Although a walking race such as this seems to involve far less risk of over exertion than has hitherto been supposed, it is, as a general test of a man's physical capabilities, in our opinion, much less satisfactory than running, and infinitely less so than a contest of the nature of a football match, which brings into play the full exer cise of every faculty as well as that of every muscle. It appeared, indeed, that endurance was the most potent factor in determining a competitor's position at the finisb, and it quickly became evident that to estimate a man's chances from consideration of his physical appearance was absolutely impossible. This conclusion was shared with us by several physiologists who were present.

The mental factor in contests of this kind is worthy of careful consideration, the man of fine sensibility neeâing enormous self.control in order to compete on equal terms with the man of blunter temperament. This was recog nized by the Committee in the provision of music during the night, and was also exemplifed in the obvious menta and physical improvement which followed the rising of the sun.

The expenses of this investigation were defrayed from the British Medical Association's grant to Dr. Pembrey, who has added to the many other kindnesses shown to us that of suggesting the lines which the present research should follow. We are also greatly indebted to Mr. A. Sandison for valuable assistance in many of these observations.

\section{IREPORE CXIX.}

\section{AURICULAR FIBRILLATION : A COMMON CLINICAL CONDITION.*}

By THOMAS LEWIS, M.D.Lond, D.Sc.Wales. (From the Research Laboratories of University College Medical School.)

\section{[A Preliminary Communication.]}

IT is well known that in the late stages of mitral stenosis, and in cases of general cardio-vascular degeneration, the pulse is frequently continuously and extremely irregular. The type of irregularity is remarkable in that in radial and cardiographic curves it defies analysis. The nature of the arterial curves has given rise to the term pulsus irregularis perpetuus, and it has been supposed that the rhythm of the heart prodacing it has its origin in the node of Tawara (bence the term "nodal rhythm"). The condition is extremely common.

Facts are now at my disposal permitting of two conclusions :

I. That a rhythm arising in the neighbourhood of the node gives rise to a totally different clinical picture. This conclusion is based upon a detailed examination (polygraphic and electrocardiographic) of a case of paroxysmal tachycardia, in which it can be demonstrated that auricle

\footnotetext{
* The expenses connected with this work have been defrayed by grants
} from the British Medical Association and the Royal Society. and iventricle contract together. This rhythm is a rare clinical phenumenon.

II. That the irregular pulse of mitral stenosis, etc., already referred to, is due to fibrillation of the auricle.

The second conclusion is based upon the following evidence:

1. The clinical irregularity presented by arterial and heart apex curres is unique. The rbythm is entirely disorderly, and the sizes of the beats do not correspond to the pauses which precede them. Fibrillation of the auricle results in a similar action of the ventricle, and its action under these circumstances is unique experimentalls.

2. Electrocardiograms taken from patients exhibiting the irregularity show a number of irregular waves, apart from the ventricular curve; they are more clearly defined in diastole. They are found in no other disorder of the heart's action. They disappear when, in a paroxysmal case, the irregularity vanishes, and are therefore due to a temporary and disorderly action of some part of the heart wall. Cardiographic curves give no evidence of such a disordered action in the ventricle. Fibrillation of the auricle yields curves which are identical in every respect, and no such curves bave been obtained by any other experimental means. Further, the waves on the experimental electrocardiograms can be shown to corre. spond to the fibrillary movements in the auricle, by means of synchronous tracings.

3. The venous curves in the clinical irregularity is of the ventricular type; all the prominent waves occur during ventricular systole, and there is no wave corresponding to a normal auricular contraction. The same statement applies to the venous curves in fibrillation of the auricle. The clinical and experimental curves are of the same nature.

The facts point clearly to the conclusion that the irregularity in question is the result of auricular fibrillation, and the conclusion affords an explanation of several otherwise obscure facts. It provides us with a rational understanding of the disorderly nature of the ventricular rhythm, for it is dependent upon the irregular auricular movements. It explains the slowing which is obtained by digitalis in those instances in which auriculo-ventriculax conduction is known to be frequently impaired-namely, in cases of rheumatic origin; for digitalis is known to increase the hindrance to the passage of the impulses where conduction is already damaged. Further it explains the difference between the type of venous pulse in the irregularity considered, and that due to what is termed "nodal extra-systole." It is in accord with the now generally accepted fact that the rhythm is supraventri, cular in origin; it harmonizes equally well with the evidence that the auricle is active in certain instances where the irregularity is present-for example, the auricular hypertrophy found at autopsy in cases succumbing with the irregularity present and of long duration. Finally, it suggests a plausible explanation of so-called "nodal bradycardia." This condition may be regarded as auricular fibrillation and spontaneous auriculoventricular heart.block. The full evidence, including the curves, will be placed on record at an early date.

THE Herbert Spencer Lecture before the University of Oxford will be delivered by Dr. G. C. Bourne, Linacro Professor of Comparative Anatomy, who has taken for his subject, " Herbert Spencer and animal evolution."

A REUTER's telegram from Peking states that considerable progress has been made in the suppression of opium smoking in the northern provinces and in Yunnan and Kwangtung, less in the central provinces, and very little in Szechuan, Kweichau, and Shensi.

THE resolution adopted at the meeting of medical practitioners on November 10th, organized by the Chelsea Division of the British Medical Association, as to paymen to medical practitioners for midwives' calls, was considered by the Fulham guardians at a meeting on November 19th, but its full discussion was adjourned to a later date. Mean. time it may be said that one member of the council held that though medical men could not point to any passage in the Act which gave them a definite claim upon guardians in this connexion, it was the undoubted duty of guardians to guarantee the payment of his fee to any medical man called in to save life during childbirth. 